\title{
Related Factors of Meeting National Cholesterol Education Program-recommended Goals with Atorvastatin
}

\author{
Yuji Yoshitomi ${ }^{1}$, Takashi Tsujibayashi ${ }^{2}$, Toshikazu Ishii ${ }^{3}$, Shun-ichiro Sakurai ${ }^{4}$, \\ Chieko Nagakura ${ }^{1}$, and Atsuyoshi Miyauchi ${ }^{1}$ \\ ${ }^{1}$ Miyauchi Makoto Memorial Clinic, Shizuoka, Japan. \\ 2 Tsujibayashi Medical Clinic, Shizuoka, Japan. \\ ${ }^{3}$ Ishii Medical Clinic, Shizuoka, Japan. \\ ${ }^{4}$ Sakurai Medical Clinic, Shizuoka, Japan.
}

\begin{abstract}
The aim of this study was to observe the efficacy of atorvastatin and the related factors of meeting the National Cholesterol Education Program (NCEP)-recommended lowdensity lipoprotein (LDL) cholesterol levels in patients with hypercholesterolemia. A total of 107 patients were treated with atorvastatin $10 \mathrm{mg} /$ day for 12 weeks. Eighty \% of the patients achieved the target goals. There was a significant difference in the initial body mass index (BMI) between patients achieving the target goals and those not achieving the target goals $(p<0.05)$. In multiple stepwise logistic regression analysis, initial BMI and complications correlated with reaching the NCEP-recommended target goals $(p<0.05)$. A great number of patients treated with atorvastatin, including those previously poorly controlled with other therapies, reached the target goals at the starting dose $10 \mathrm{mg} / \mathrm{day}$. BMI may be a useful index of achieving the NCEP-recommended target goals with atorvastatin. J Atheroscler Thromb, 2003; 10: 19-24.
\end{abstract}

Key words: Atorvastatin, Body mass index, National Cholesterol Education Program

\section{Introduction}

Various genetic and environmental factors contribute to the development and progression of atherosclerotic disease. The importance of hypercholesterolemia as a risk factor for coronary artery disease and the ability of cholesterol-lowering drugs to reduce the incidence of coronary heart disease or delay its progression is well established $(1,2)$. In 1993, the Adult Treatment Panel (ATP-II) report of the National Cholesterol Education Program (NCEP) outlined an updated systematic clinical approach to treating high blood cholesterol in adults (3). The expert panel recommends lipid-lowering drug treatment if, after an attempt at dietary intervention, low-density lipoprotein (LDL)

Address for correspondence: Yuji Yoshitomi, MD, Miyauchi Makoto Memorial Clinic, 9-44 Izumi-cho, Mishima, Shizuoka 411-0037, Japan.

E-mail: ytommy@sage.ocn.ne.jp

Received July 30, 2002.

Accepted for publication September 18, 2002. cholesterol remains $\geq 4.80 \mathrm{mmol} / \mathrm{l}$ in patients with less than 2 coronary heart disease (CHD) risk factors or $\geq 4.13$ $\mathrm{mmol} / \mathrm{I}$ in patients with 2 or more CHD risk factors. However, 3-hydroxy-3-methylglutaryl coenzyme A (HMG-CoA) reductase inhibitors such as pravastatin and simvastatin have a rather limited capacity for lowering LDL cholesterol levels (4-6). Atorvastatin is a HMG-CoA reductase inhibitor that has been shown to lower LDL cholesterol $41 \%$ to $60 \%$ over its effective dose range $(7,8)$. We assessed the percentage of patients administered with atorvastatin reaching the NCEP-recommended target goals and its relational factors in patients with primary hypercholesterolemia and mixed hypercholesterolemia.

\section{Methods}

\section{Patient selection}

Patients with primary hypercholesterolemia and mixed hypercholesterolemia entered this open-label, observational study at four primary care centres in Shizuoka, Ja- 
pan. Eligible patients were aged 18 to 85 years with body mass index $(\mathrm{BMI})<35 \mathrm{~kg} / \mathrm{m}^{2}$. The inclusion criteria were plasma LDL cholesterol $>4.14 \mathrm{mmol} / \mathrm{l}$ and plasma triglycerides (TG) below $4.52 \mathrm{mmol} / \mathrm{l}$. Patients on lipid-lowering medication were allowed to participate if they met the inclusion criteria during treatment. We did not have a washout period. Patients were ineligible if they had active liver disease, or hepatic or renal dysfunction. Women with childbearing potential were also ineligible. Study participants could not concurrently take drugs known to affect lipid levels or known to interact with the study medication.

The enrolled patients started initial treatment of hyperlipidemia (Group I) or had taken a lipid-lowering drug previously (Group II). In group II, most (95\%) were receiving statins, whereas $4 \%$ were receiving fibrates and $1 \%$ other drugs. All the previous drugs were replaced with atorvastatin. The detailed entry criteria for the study was 1) $\mathrm{LDL}$ cholesterol $\geq 4.80 \mathrm{mmol} / \mathrm{l}$ in patients without $\mathrm{CHD}$ and with fewer than two risk factors as described by the NCEP-ATP II, 2) LDL cholesterol $\geq 4.13 \mathrm{mmol} / \mathrm{l}$ in those without $\mathrm{CHD}$ and with two or more risk factors, or 3 ) LDL cholesterol $\geq 3.36 \mathrm{mmol} / \mathrm{l}$ in those with $\mathrm{CHD}$ (3). Eligible patients were administered a fixed dose of atorvastatin $10 \mathrm{mg}$ per day. Patients were required to adhere to the NCEP Step I diet or a similar diet during the follow-up period.

The target goals of therapy were to reduce LDL cholesterol to: 1) $4.13 \mathrm{mmol} / \mathrm{l}$ or less if fewer than two other risk factors without $\mathrm{CHD}$ were present, 2) $3.36 \mathrm{mmol} / \mathrm{l}$ or less if two (or more) risk factors without CHD were present, or 3 ) $2.59 \mathrm{mmol} / \mathrm{l}$ or less if CHD were present (3). Obesity was measured in terms of initial BMI before treatment. It was dichotomized with $25 \mathrm{~kg} / \mathrm{m}^{2}$ as the cutoff point (9). The objectives and implications of the study were explained to the patients according to the Declaration of Helsinki.

\section{Laboratory methods}

Fasting blood samples were drawn at the baseline and after 12 weeks of treatment for all lipid analyses. Patients in group II underwent laboratory examinations while taking their previous drugs. Total cholesterol, high-density lipoprotein (HDL) cholesterol, and TG were measured by enzymatic methods. LDL cholesterol was estimated by the formula ( $\mathrm{LDL}$ cholesterol = total cholesterol $-\mathrm{HDL}$ cholesterol $-\mathrm{TG} \times 0.2$ [10]).

\section{Efficacy and safety evaluation}

At each visit, patients were asked about their health status and adverse events, and investigators assessed these events in terms of intensity, duration, relation to study medication, and clinical outcome. A full clinical laboratory evaluation (routine hematology and blood chemistry testing) was done at screening and 12 weeks, while safety evaluations (alanine aminotransferase, aspartate ami- notransferase and creatine phosphokinase) were performed during the study period. Adverse events were recorded at each clinic visit. Associated adverse events were those the investigator judged definitely, probably or possibly related to treatment as well as those for which the investigator indicated an unknown relationship to treatment or insufficient available information for evaluation.

\section{Statistical Analysis}

Data were expressed as the mean \pm standard deviation (for normally distributed variables) and percentage (for categorical variables). The comparison of continuous variables between the groups was performed with the paired or unpaired Student's $t$ test (two-tailed) for normally distributed data or the Mann-Whitney $U$ test for the other data. Comparisons of categorical variables were made by $\chi^{2}$ and Fisher exact tests as appropriate. Univariate logistic regression analysis was used to select the independent predictive factors for achieving target goals within the entire study population. The covariates examined included clinical characteristics (age, sex, initial BMI, risk factors, and complications), and pre-treatment lipid values (total cholesterol, LDL cholesterol, HDL cholesterol, and TG). Univariate predictors of achieving target goals with a $p$ value $<0.05$ were entered into a multivariate logistic regression model with stepwise selection. Differences were considered statistically significant at a value of $p<0.05$.

\section{Results}

\section{Patients}

A total of 107 patients (27 men, 80 women) were treated with atorvastatin $10 \mathrm{mg} /$ day; 33 with less than 2 risk factors and 63 with 2 or more risk factors. Eleven patients had CHD (Table 1). The mean age was $63 \pm 11$ years with $28 \%$ of the patients $\geq 70$ years. Median initial BMI was $24.1 \mathrm{~kg} / \mathrm{m}^{2}$, with a range of the group median values from 23.5 to $25.5 \mathrm{~kg} / \mathrm{m}^{2}$.

\section{Efficacy analysis}

Mean percent reductions from the baseline in LDL cholesterol levels were $36 \pm 20 \%$. TG levels decreased $6 \pm$ $47 \%$, and HDL cholesterol levels increased $3 \pm 25 \%$. Age, sex, initial BMI, risk factors, and complications did not differ between Group I and Group II (Table 1). There were significant differences in total cholesterol levels and LDL cholesterol levels between the 2 groups before treatment.

There was a significant difference in initial BMI between patients achieving the target goals and those not achieving the target goals $(p<0.05)$ (Table 2). LDL cholesterol levels before and after treatment in patients achieving the target goals were lower than in those not achieving the target goals $(p<0.001)$. 
Table 1. Clinical Characteristics and lipid values between the 2 groups

\begin{tabular}{|c|c|c|c|}
\hline & $\begin{array}{l}\text { All patients } \\
(n=107)\end{array}$ & $\begin{array}{l}\text { Starting treatment group } \\
(\text { Group I })(n=38)\end{array}$ & $\begin{array}{l}\text { Previous treatment group } \\
\text { (Group II) }(n=69)\end{array}$ \\
\hline Age (years) & $63 \pm 11$ & $63 \pm 10$ & $63 \pm 11$ \\
\hline $\operatorname{Sex}(M / F)$ & $27 / 80$ & $8 / 30$ & $19 / 50$ \\
\hline Initial BMI (kg/m²) & $24.1 \pm 3.5$ & $23.8 \pm 3.4$ & $24.3 \pm 3.5$ \\
\hline \multicolumn{4}{|l|}{ Risk factors } \\
\hline Hypertension & $61(57)$ & $21(55)$ & $43(62)$ \\
\hline Diabetes Mellitus & $25(23)$ & $11(29)$ & $14(20)$ \\
\hline Smoking & $12(11)$ & $4(11)$ & $8(12)$ \\
\hline \multicolumn{4}{|l|}{ Complications } \\
\hline Angina pectoris & $8(7)$ & $3(8)$ & $5 \quad(7)$ \\
\hline Myocardial infarction & 3 (3) & 1 (3) & $2(3)$ \\
\hline \multicolumn{4}{|l|}{ Lipid values before treatment } \\
\hline Total cholesterol (mmol/l) & $6.98 \pm 0.81$ & $7.33 \pm 0.94^{\star \star}$ & $6.79 \pm 0.67$ \\
\hline LDL cholesterol (mmol/l) & $4.53 \pm 0.75$ & $4.77 \pm 0.87^{\star \star *}$ & $4.40 \pm 0.65$ \\
\hline HDL cholesterol (mmol/l) & $1.58 \pm 0.48$ & $1.63 \pm 0.42$ & $1.55 \pm 0.51$ \\
\hline Triglycerides (mmol/l) & $1.97 \pm 1.03$ & $2.12 \pm 1.06$ & $1.88 \pm 1.00$ \\
\hline \multicolumn{4}{|l|}{ Lipid values after 12 weeks } \\
\hline Total cholesterol (mmol/l) & $5.24 \pm 1.09$ & $4.95 \pm 0.80^{\star \star \star}$ & $5.40 \pm 1.20$ \\
\hline LDL cholesterol (mmol/l) & $2.93 \pm 1.07$ & $2.63 \pm 0.76^{\star \star \star}$ & $3.10 \pm 1.18$ \\
\hline HDL cholesterol (mmol/l) & $1.56 \pm 0.43$ & $1.57 \pm 0.40$ & $1.56 \pm 0.45$ \\
\hline Triglycerides (mmol/l) & $1.71 \pm 1.03$ & $1.67 \pm 0.95$ & $1.73 \pm 1.07$ \\
\hline
\end{tabular}

Values are expressed as mean \pm SD or number (\%) of patients.

${ }^{*} p<0.001,{ }^{* \star} p<0.01,{ }^{\star \star *} p<0.05$ vs previous treatment group.

$\mathrm{BMI}=$ body mass index; $\mathrm{LDL}=$ low-density lipid; HDL = high-density lipid

Table 2. Clinical Characteristics and lipid values between the 2 groups with or without meeting the target goal

\begin{tabular}{|c|c|c|}
\hline & $\begin{array}{c}\text { Achieving target } \\
(n=86)\end{array}$ & $\begin{array}{c}\text { Not achieving target } \\
\qquad(n=21)\end{array}$ \\
\hline Age (years) & $63 \pm 10$ & $61 \pm 13$ \\
\hline $\operatorname{Sex}(M / F)$ & $20 / 66$ & $7 / 14$ \\
\hline Initial BMI (kg/m²) & $23.7 \pm 3.4^{\star \star *}$ & $25.7 \pm 3.3$ \\
\hline Previous lipid-lowering drugs & $51(59)$ & $16(76)$ \\
\hline \multicolumn{3}{|l|}{ Risk factors } \\
\hline Hypertension & $51(59)$ & $12(57)$ \\
\hline Diabetes Mellitus & $18(21)$ & $5(24)$ \\
\hline Smoking & $9(10)$ & $3(14)$ \\
\hline \multicolumn{3}{|l|}{ Complications } \\
\hline Angina pectoris & $6(7)$ & $2(10)$ \\
\hline Myocardial infarction & $2(2)$ & $1(5)$ \\
\hline \multicolumn{3}{|l|}{ Lipid values before treatment } \\
\hline Total cholesterol (mmol/l) & $6.91 \pm 0.68^{\star \star \star}$ & $7.34 \pm 1.18$ \\
\hline LDL cholesterol (mmol/l) & $4.41 \pm 0.64^{*}$ & $5.05 \pm 0.93$ \\
\hline HDL cholesterol (mmol/l) & $1.61 \pm 0.51$ & $1.43 \pm 0.34$ \\
\hline Triglycerides (mmol/l) & $1.98 \pm 1.03$ & $2.00 \pm 1.06$ \\
\hline \multicolumn{3}{|l|}{ Lipid values after 12 weeks } \\
\hline Total cholesterol (mmol/l) & $5.03 \pm 0.65^{\star}$ & $6.10 \pm 1.88$ \\
\hline LDL cholesterol (mmol/l) & $2.68 \pm 0.59^{\star}$ & $3.93 \pm 1.78$ \\
\hline HDL cholesterol (mmol/l) & $1.60 \pm 0.45$ & $1.41 \pm 0.32$ \\
\hline Triglycerides (mmol/l) & $1.70 \pm 1.03$ & $1.74 \pm 1.06$ \\
\hline
\end{tabular}

Values are expressed as mean \pm SD or number (\%) of patients.

${ }^{\star} p<0.001,{ }^{* *} p<0.01,{ }^{* *} p<0.05$ vs not achieving target group.

$\mathrm{BMI}=$ body mass index; $\mathrm{LDL}=$ low-density lipid; $\mathrm{HDL}=$ high-density lipid 


\section{Subgroup analysis}

Before treatment, there were no significant differences in total cholesterol, LDL cholesterol, and HDL cholesterol levels between the overweight subjects (initial BMI $\geq 25$ $\mathrm{kg} / \mathrm{m}^{2}$ ) and lean subjects (initial BMI $<25 \mathrm{~kg} / \mathrm{m}^{2}$ ) (Table 3). TG levels before treatment tended to be higher in overweight subjects than in lean subjects, but not significantly $(p=0.06)$. However, TG levels after 12 weeks differed between the 2 groups $(p<0.05)$. A significant greater percentage of lean subjects achieved the target goal compared with overweight subjects.

\section{Univariate and multivariate logistic regression analysis}

By univariate logistic regression analysis, initial BMI and complications were significant variables for reaching the NCEP-recommended target goals (Table 4). LDL cholesterol levels before treatment did not contribute to reaching the NCEP-recommended target goals. In multiple stepwise logistic regression analysis, those 2 parameters correlated with reaching the NCEP-recommended target goals.

\section{Safety}

All patients completed the study for 12 weeks. None of the serious adverse events (hospitalization, cancer, overdose, and death) were considered associated treatment. Four of the 107 patients were withdrawn. There were 2 patients with mild elevations (two to three times the reference range) of transaminase. Only one patient expressed persistent transaminase elevations greater than 3 times the upper limit of the normal range. One patient showed arthlargia. No patient had elevations of creatine kinase greater than 10 times the upper limit of normal.

\section{Discussion}

Obesity is frequently associated with insulin resistance and abnormal glucose homeostasis. Tumor necrosis factor-alpha plays an important role in mediating the insulin resistance of obesity through its overexpression in fat tissue (11). A recent study in an animal model indicated that chronic hyperinsulinemia reduces antilipolysis by downregulating mRNA for insulin receptor substrate-2, an essential component of the insulin-signaling pathway in liver, and activates fatty acid synthesis (12). Insulin-resistance associated with compensatory hyperinsulinemia is frequently linked to hypertriglyceridemia. In our study, triglycerides after treatment were still higher in overweight subjects. Further studies are required to clarify the relationship between the LDL cholesterol lowering efficacy of atorvastatin and hyperinsulinemia.

Alternatively, obesity was associated with an increased cholesterol synthetic rate equal to $20 \mathrm{mg} /$ day for each

Table 3. Clinical Characteristics and lipid values between overweight subjects and lean subjects

\begin{tabular}{|c|c|c|}
\hline & $\begin{array}{l}\text { Lean subjects } \\
\qquad(n=66)\end{array}$ & $\begin{array}{l}\text { Overweight subjects } \\
\qquad(n=41)\end{array}$ \\
\hline Age (years) & $63 \pm 11$ & $63 \pm 9$ \\
\hline $\operatorname{Sex}(M / F)$ & $18 / 48$ & $9 / 32$ \\
\hline Initial BMI (kg/m²) & $22.1 \pm 2.1^{\star *}$ & $27.5 \pm 2.5$ \\
\hline \multicolumn{3}{|l|}{ Risk factors } \\
\hline Hypertension & $35(53)$ & $29(71)$ \\
\hline Diabetes Mellitus & $15(23)$ & $10(24)$ \\
\hline Smoking & $9(14)$ & $3(7)$ \\
\hline \multicolumn{3}{|l|}{ Complications } \\
\hline Angina pectoris & 4 (6) & $4(10)$ \\
\hline Myocardial infarction & 1 (2) & $2(5)$ \\
\hline \multicolumn{3}{|l|}{ Lipid values before treatment } \\
\hline Total cholesterol (mmol/l) & $6.97 \pm 0.72$ & $7.00 \pm 0.96$ \\
\hline LDL cholesterol (mmol/l) & $4.53 \pm 0.66$ & $4.53 \pm 0.89$ \\
\hline HDL cholesterol (mmol/l) & $1.62 \pm 0.50$ & $1.52 \pm 0.44$ \\
\hline Triglycerides (mmol/l) & $1.86 \pm 1.03$ & $2.14 \pm 1.01$ \\
\hline \multicolumn{3}{|l|}{ Lipid values after 12 weeks } \\
\hline Total cholesterol (mmol/l) & $5.11 \pm 0.76$ & $5.46 \pm 1.46$ \\
\hline LDL cholesterol (mmol/l) & $2.82 \pm 0.73$ & $3.11 \pm 1.45$ \\
\hline HDL cholesterol (mmol/l) & $1.61 \pm 0.46$ & $1.49 \pm 0.37$ \\
\hline Triglycerides (mmol/l) & $1.54 \pm 1.01^{*}$ & $1.98 \pm 1.02$ \\
\hline Reaching target goals & $57(86)^{\star}$ & $27(66)$ \\
\hline
\end{tabular}

Values are expressed as mean \pm SD or number (\%) of patients.

${ }^{*} p<0.05,{ }^{* *} p<0.001$ vs overweight subjects.

$\mathrm{BMI}=$ body mass index; $\mathrm{LDL}=$ low-density lipid; $\mathrm{HDL}=$ high-density lipid 
Table 4. Univariate predictors of achieving the target goals

\begin{tabular}{|c|c|c|c|}
\hline & Univariate coefficient & Standard error & $P$ value \\
\hline Age & -0.002 & 0.003 & 0.396 \\
\hline Sex & -0.053 & 0.078 & 0.498 \\
\hline Initial BMI & -0.229 & 0.010 & 0.026 \\
\hline Previous treatment & -0.135 & 0.089 & 0.133 \\
\hline Previous drugs & -0.006 & 0.011 & 0.584 \\
\hline Diabetes Mellitus & -0.006 & 0.077 & 0.460 \\
\hline Hypertension & 0.066 & 0.067 & 0.333 \\
\hline Smoking & 0.057 & 0.023 & 0.871 \\
\hline Complications & -0.404 & 0.097 & 0.001 \\
\hline Total cholesterol levels at baseline & 0.001 & 0.003 & 0.867 \\
\hline LDL cholesterol levels at baseline & -0.005 & 0.004 & 0.124 \\
\hline HDL cholesterol levels at baseline & -0.001 & 0.001 & 0.535 \\
\hline Triglycerides levels at baseline & -0.002 & 0.003 & 0.627 \\
\hline
\end{tabular}

$\mathrm{BMI}=$ body mass index; $\mathrm{LDL}=$ low-density lipid; $\mathrm{HDL}=$ high-density lipid

kilogram of body fat (13). It is possible that the activity of the HMG-CoA reductase increases in overweight subjects. Although the pharmacological action was different, Post hoc analysis of the Helsinki Heart Study with gemfibrozil suggested that the decrease in LDL cholesterol levels was more pronounced in subjects with a BMI below the median value (14). Lean subjects may benefit more from atorvastatin treatment than overweight subjects.

Statins have consistent and acceptable safety profiles, as evidenced by their widespread exposure in currently marketed compounds: lovastatin, pravastatin, simvastatin, and fluvastatin $(5,15,16)$. This study coincided with previous reports that clearly established atorvastatin as an efficacious HMG-CoA reductase inhibitor for lowering LDL cholesterol. Recently, aggressive LDL cholesterol reduction by atorvastatin has been associated with greater regression of the carotid intima media thickness measured by quantitative B-mode ultrasound in patients with familial hypercholesterolemia, compared with simvastatin (17).

Hunninghake et al. suggested that a significantly greater percentage $(71 \%)$ of $10 \mathrm{mg}$ once daily atorvastatin-treated patients achieved the NCEP-recommended target goals after 12 weeks of treatment (18), while another report revealed that $32 \%$ of $10 \mathrm{mg}$ atorvastatin-treated patients achieved the NCEP-recommended target goals after 12 weeks in patients with documented atherosclerosis (19). The discrepancy was attributed to differences in patient selection. At week 12, $80 \%$ of patients with fixed doses of $10 \mathrm{mg}$ once daily reached their NCEP-recommended target goals in this study. The excellent result of atorvastatin for achieving NCEP-recommended target goals may result in less combination therapy, a low discontinuation rate, and high compliance.

Among more than 4,000 patients treated with atorvastatin, persistent transaminase elevations greater than 3 times the upper limit of the normal range were re- ported for 30 patients $(0.7 \%)(20)$. There was a doserelated increase in the number of patients with mild elevations of transaminase (one to two times the reference range) (7). On the other hand, in a long term study with atorvastatin in which all patients were treated for a comparable period, no dosage-related increase in minor elevations was observed (8). Alanine aminotransferase elevations greater than 3 times the upper limit of the normal range were examined according to stratification by age, sex, height, alcohol consumption, BMI, and final LDL cholesterol level. None of these variables was related to the incidence of alanine aminotransferase elevations greater than 3 times the upper limit of the normal range (20). To date, whether more frequent adverse events occur as a result of increased LDL cholesterol reduction remains obscure.

The study did not consist of a dietary baseline phase in patients with previous lipid-lowering treatment. Therefore, we took note of whether patients given atorvastatin achieve the NCEP-recommended LDL cholesterol target goals.

In conclusion, atorvastatin, with its enhanced efficacy, provides adequate therapy for a large number of dyslipidemic patients, including those previously poorly controlled with other therapies. With atorvastatin therapy, patients may be able to achieve the NCEP-recommended target goals in a shorter period of time. BMI may be a useful index of achieving NCEP-recommended target goals with atorvastatin.

\section{References}

(1) Scandinavian Simvastatin Survival Study Group: Randomized trial of cholesterol lowering in 4444 patients with coronary heart disease: Scandinavian Simvastatin Survival Study (4S). Lancet, 344: 13831389, 1994 
(2) Holmes I: An analysis of randomized trials evaluating the effect of cholesterol reduction on total mortality and coronary heart disease incidence. Circulation, 82: 1916-1924, 1990

( 3 ) Expert panel on detection, evaluation, and treatment of high blood cholesterol in adults. Summary of the second report of the National Cholesterol Education Program (NCEP) expert panel on detection, evaluation, and treatment of high blood cholesterol in adults (adult treatment panel II). JAMA, 269: 30153024, 1993

( 4 ) Davignon J, Montigny M, and Dufour R: HMG-CoA reductase inhibitors: a look back and a look ahead. Can J Cardiol, 8: 843-864, 1992

( 5 ) Shephed J: Statins. Is there a need for alternative or adjunctive therapy? Br Heart J, 74: 13, 1995

(6) Rubenfire M, Maciejko JJ, Blevins RD, Orringer C, Kobylak L, Rosman H, and Southeastern Michigan Collaborative Group: The effect of pravastatin on plasma lipoprotein and apolipoprotein levels in primary hypercholesterolemia. Arch Intern Med, 151: 2234-2240, 1991

( 7 ) Nawrocki JW, Weiss SR, Davidson MH, Sprecher DL, Schwartz SL, Lupien PJ, Jones PH, Haber HE, and Black DM: Reduction of LDL cholesterol by $25 \%$ to $60 \%$ in patients with primary hypercholesterolemia by atorvastatin, a new HMG-CoA reductase inhibitor. Arterioscler Thromb Vasc Biol, 15: 678-682, 1995

( 8 ) Davidson M, McKenney J, Stein E, Schrott H, Bakker-Arkema R, Fayyad R, and Black D: Comparison on one-year efficacy and safety of atorvastatin versus lovastatin in primary hypercholesterolemia: Atorvastatin Study Group I. Am J Cardiol, 79: 14751481, 1997

(9) Garrow JS: Obesity. In: Oxford Textbook of Medicine. 3rd Ed, ed by Ledingham JGG, Weatherall DJ, Warrell DA, pp 1301-1314, Oxford Medical Publications, Oxford, New York, 1999

(10) Freidewald WT, Levy RI, and Fredrikson DS: Estimation of the concentration of low density lipoprotein cholesterol in plasma without the use of a centrifuge. Clin Chem, 18: 449-502, 1972

(11) Hotamisligil GS, Arner P, Caro JF, Atkinson RL, and Spiegelman BM: Increased adipose tissue expression of tumor necrosis factor-alpha in human obesity and insulin resistance. J Clin Invest, 95: 24092415, 1995
(12) Shimomura I, Matsuda M, Hammer RE, Bashmakov Y, Brown MS, and Goldstein JL: Decreased IRS-2 and increased SREBP-1c lead to mixed insulin resistance and sensitivity in livers of lipodystrophic and ob/ob mice. Mol Cell, 6: 77-86, 2000

(13) Schreibman PH and Dell RB: Human adipocyte cholesterol. Concentration, localization, synthesis, and turnover. J Clin Invest, 55: 986-993, 1975

(14) Manninen V, Elo MO, Frick MH, Haapa K, Heinonen OP. Heinsalmi P, Helo P, Huttunen JK, Kaitaniemi P, Koskinen P, Menp, Mlknen M, Mnttri M, Norola S, Pasternack A, Pikkarainen J, Sjblom T, and Nikkil EA: Lipid alterations and decline in the incidence of coronary heart disease in the Helsinki Heart Study. JAMA, 260:641-651, 1988

(15) Hsu I, Spinler SA, and Johnson NE: Comparative evaluation of the safety and efficacy of HMG-CoA reductase inhibitor monotherapy in the treatment of primary hypercholesterolemia. Ann Pharmacother, 29:743-759, 1995

(16) Shepherd J: Fibrates and statins in the treatment of hyperlipidemia: an appraisal of their efficacy and safety. Eur Heart J, 16:5-13, 1995

(17) Smilde TJ, Wissen van S, Wollersheim H, Trip MD, Kastelein JJP, and Stalenhoef AFH: Effect of aggressive versus conventional lipid lowering on atherosclerosis progression in familial hypercholesterolemia (ASAP): a prospective, randomized, double-blind trial. Lancet, 357: 577-581, 2001

(18) Hunninghake D, Bakker-Arkema RG, Wigand JP, Drehobl M, Schrott H, Early JL, Abdallah P, McBride $S$, and Black DM: Treating to meet NCEP-recommended LDL cholesterol concentrations with atorvastatin, fluvastatin, lovastatin, or simvastatin in patients with risk factors for coronary heart disease. J Fam Pract, 47: 349-356, 1998

(19) Brown AS, Bakker-Arkema RG, Yellen L, Henley RW, Guthrie R, Campbell CF, Koren M, Woo W, McLain $\mathrm{R}$, and Black DM: Treating patients with documented atherosclerosis to National Cholesterol Education Program-Recommended low-density-lipoprotein cholesterol goals with atorvastatin, fluvastatin, lovastatin and simvastatin. J Am Coll Cardiol, 32: 665-672, 1998

(20) Black DM, Bakker-Arkema RG, and Nawrocki JW: An overview of the clinical safety profile of atorvastatin (Lipitor), a new HMG-CoA reductase inhibitor. Arch Inter Med, 158: 577-584, 1998 